\title{
Reliability of the Canadian Triage and Acuity Scale: interrater and intrarater agreement from a community and an academic emergency department
}

\author{
Christopher M.B. Fernandes, MD*; Shelley McLeod, MSc*; Joel Krause, MD*; Amit Shah, MD*;
} Justine Jewell, $\mathrm{RN}^{*}$; Barbara Smith, $\mathrm{RN}^{\dagger}$; Lorraine Rollins, $\mathrm{RN}^{\dagger}$

\section{ABSTRACT}

Objectives: The Canadian Triage and Acuity Scale (CTAS) is a five-level triage tool that is used to help prioritize the order in which emergency department (ED) patients should be seen. The objectives of this study were to determine the interrater and intrarater agreement of the 2008 CTAS guideline revisions by triage nurses and to compare agreement between triage nurses working in a small community ED and an academic ED.

Methods: Seventy-eight triage nurses assigned CTAS scores and free-text presenting complaints for 10 paper-based case scenarios. For five scenarios, the CTAS score should have remained unchanged from previous guidelines, whereas the other five scenarios should have been triaged differently based on the 2008 CTAS first-order modifiers. Thirty-three participants repeated the questionnaire 90 days later, and intrarater agreement was measured.

Results: There was a higher level of agreement $(\kappa=0.73$; $95 \% \mathrm{Cl} 0.68-0.79)$ for the five case scenarios, which relied on the older 2004 guidelines compared to the scenarios where the 2008 guidelines would have suggested a different triage level $(\kappa=0.50 ; 95 \% \mathrm{Cl} 0.42-0.59)$. For the 10 case scenarios analyzed, the free-text presenting complaints matched the Canadian Emergency Department Information System (CEDIS) list $90.1 \%$ of the time $(\kappa=$ 0.80; 95\% Cl 0.76-0.84).

Conclusion: The reliability of CTAS scoring by academic and community ED nurses was relatively good; however, the application of the 2008 CTAS revisions appears less reliable than the 2004 CTAS guidelines. These results may be useful to develop educational materials to strengthen reliability and validity for triage scoring using the 2008 CTAS guideline revisions.

RÉSUMÉ

Objectifs: L'Échelle canadienne de triage et de gravité (ECTG) est un outil de triage à cinq niveaux, qui aide le personnel à déterminer l'ordre dans lequel les patients devraient être vus aux services des urgences (SU). La présente étude avait pour objectifs de déterminer la concordance interévaluateurs et intraévaluateurs des cotes attribuées par le personnel infirmier affecté au triage, d'après les lignes directrices de I'ECTG révisées en 2008 , et de comparer la concordance entre le personnel infirmier affecté au triage dans un petit SU communautaire et dans un SU de centre hospitalier universitaire.

Méthode: Soixante-huit infirmières et infirmiers affectés au triage ont attribué des cotes selon I'ECTG et décrit librement les symptômes ayant motivé la consultation dans 10 scénarios fictifs. Dans cinq d'entre eux, le résultat obtenu à I'ECTG aurait dû rester le même d'après les anciennes lignes directrices, tandis que dans les cinq autres scénarios le niveau de triage aurait dû être différent d'après les modifications de 2008, apportées aux descripteurs de premier rang de I'ECTG. Trente-trois participants ont repris le questionnaire 90 jours plus tard, après quoi il y a eu mesure de la concordance intraévaluateurs.

Résultats: Il y avait un degré élevé de concordance ( $\kappa=0.73$; IC à $95 \% 0.68-0.79$ ) en ce qui concerne les cinq scénarios, qui reposaient sur les anciennes lignes directrices de 2004 comparativement aux scénarios qui, d'après les lignes directrices de 2008, auraient dû recevoir un niveau différent

From the *Division of Emergency Medicine, Schulich School of Medicine \& Dentistry, Western University, and Department of Emergency Medicine, London Health Sciences Centre, London, ON; and tDepartment of Emergency Medicine, St. Thomas Elgin General Hospital, St. Thomas, ON.

Presented at the Canadian Association of Emergency Physicians Annual Conference, May/Jun 2010, Montreal, PO.

Correspondence to: Dr. Christopher Fernandes, E1-120, Westminster Tower, 800 Commissioners Road East, London, ON N6A 5W9; christopher. fernandes@Ihsc.on.ca.

This article has been peer reviewed. 
de triage $(\kappa=0.50$; IC à $95 \% 0.42-0.59$ ). Quant aux 10 scénarios analysés, la description libre des symptômes coïncidait avec la liste du Canadian Emergency Department Information System (CEDIS) $90.1 \%$ des fois ( $\kappa=0.80$; IC à 95 $\%$ 0.76-0.84).

Conclusions: La fiabilité des cotes de triage selon I'ECTG, attribuées par le personnel infirmier dans le SU communautaire et dans le SU universitaire était relativement bonne; toutefois, I'application des nouveaux descripteurs de 2008 semble moins fiable que celle des lignes directrices de 2004. Ces résultats pourraient être utiles dans l'élaboration de matériel didactique visant à accroître la fiabilité et la validité des cotes de triage, accordées d'après les lignes directrices de l'ECTG révisées en 2008.

Keywords: agreement, Canadian Triage and Acuity Scale (CTAS), reliability
The Canadian Triage and Acuity Scale (CTAS) has been widely implemented in Canadian emergency departments (EDs), as well as internationally, since 1999. ${ }^{1-4}$ It is used for prioritizing the order in which patients should be seen by an emergency physician.

From its inception, the CTAS was intended to be subjected to longitudinal review to confirm interobserver agreement and ensure that there would be no manipulation of the triage process. ${ }^{5}$ The CTAS was also intended to evolve over time to meet the needs of EDs. The CTAS National Working Group has implemented multiple revisions to the original guidelines to make the triage process more standardized and objective, with the goal of improving interrater and intersite reliability. ${ }^{6,7}$ Revisions were made to the CTAS in 2004 that involved first-order and secondorder modifiers to allow triage nurses to "uptriage" patients based on various factors, including vital signs, level of consciousness, pain severity, mechanism of injury, blood glucose, and obstetric complaints. ${ }^{6}$ These modifications have been accepted and applied without any published postapplication reliability investigations.

As part of the triage process, the triage nurse must assign a CTAS score and enter a presenting complaint. In most EDs across Canada, the presenting complaint is a free-text entry summarizing the patient's selfreported reason for the visit. ${ }^{8}$ One of the goals of the Canadian Emergency Department Information System (CEDIS) national working group was to develop a comprehensive and standardized ED data set for Canada. One of the outputs of the CEDIS national working group has been the publication and revision of a standardized list of 165 common ED presenting complaints. ${ }^{8-10}$

The objectives of this study were to determine the interrater and intrarater agreement of the 2008 CTAS guideline revisions by all triage nurses and to compare agreement between triage nurses working in a small community ED and an academic ED.

\section{METHODS}

Triage nurses working in the ED of an academic tertiary care centre affiliated with Western University (annual census 65,000) and a nearby community hospital ED (annual census 35,000) were invited to complete a questionnaire containing 10 paper-based ED case scenarios. To participate, nurses must have worked as a triage nurse for a minimum of 1 year and must have completed standardized training using the national test training materials that have been developed to support the implementation of the 2004 and 2008 CTAS guidelines. Nurses independently assigned triage scores and free-text presenting complaints to 10 paper-based case scenarios (Appendix) consisting of vital signs, patient age, pain score, and a general description of the reason for the visit. For five scenarios, the CTAS score should have remained unchanged, whereas the other five scenarios should have been differently triaged based on the 2008 CTAS first-order and second-order modifiers. An expert in triage training and clinical education assigned a CEDIS presenting complaint to each paper-based case scenario. The free-text presenting complaints that were assigned by the participants were assessed to determine if there was a matching CEDIS presenting complaint; interobserver agreement between nurses was then measured.

The first iteration of the survey was completed in July 2009, and participants were asked to repeat the questionnaire 90 days later. The case scenarios were developed by the authors (ED clinical educators, triage nurses, emergency physicians, and an epidemiologist). Prior to distribution, all cases were peer reviewed for ease of language and comprehension. Participants were not given any indication about the content or purpose of the questionnaire, and completion of the survey was proctored by one of the authors (J.K., S.M., or L.R.) to ensure that there was no communication between participants. 
Data were entered directly into a study-specific Microsoft Excel database (Microsoft Corporation, Redmond, WA). Interrater and intrarater reliability were estimated using both linear-weighted and quadraticweighted kappa $(\kappa)$ statistics, with $\kappa<0.2$ interpreted as "poor agreement," $\kappa=0.2$ to 0.4 interpreted as "fair agreement," $\kappa=0.41$ to 0.60 interpreted as "moderate agreement," $\kappa=0.61$ to 0.80 interpreted as "good agreement," and $\kappa>0.80$ interpreted as "very good agreement." ${ }_{11}$ Descriptive statistics were summarized using means and standard deviations. All data analyses were performed using SPSS 13.0 (SPSS Inc, Chicago, IL).

Approval for this research study was obtained from the Health Sciences Research Ethics Board of Western University. Participation was voluntary, and the results are presented anonymously.

\section{RESULTS}

Seventy-eight triage nurses participated in the study. Fifty-three $(67.9 \%)$ nurses were from the academic teaching ED and 25 (32.1\%) were from the community ED. Sixty-four nurses $(83.1 \%)$ were female, and the participants had a mean (SD) of 8.9 (7.3) years of ED triage experience.

For the 10 case scenarios analyzed, exact modal agreement for all 78 nurses was good $(\kappa=0.70 ; 95 \%$ CI 0.66-0.74; quadratic-weighted $\kappa=0.79)$. There was a trend toward a higher level of agreement between triage nurses from the community hospital $(\kappa=0.78$; 95\% CI 0.71-0.84; quadratic-weighted $\kappa=0.84)$ compared to those from the teaching hospital $(\kappa=$ 0.67 ; $95 \%$ CI 0.62-0.72; quadratic-weighted $\kappa=0.77$ ). Thirty-three $(42.3 \%)$ participants repeated the questionnaire 90 days later. Intrarater agreement for nurses who repeated the questionnaire was good $(\kappa=0.74$; 95\% CI 0.68-0.80; quadratic-weighted $\kappa=0.83$ ). Community hospital triage nurses had a similar level of intrarater agreement $(\kappa=0.76 ; 95 \%$ CI $0.68-0.85$; quadratic-weighted $\kappa=0.84)$ compared to their colleagues at the teaching hospital $(\kappa=0.73 ; 95 \%$ CI 0.65-0.80; quadratic-weighted $\kappa=0.83$ ).

The level of agreement was significantly higher for the five case scenarios that relied on the 2004 CTAS guidelines $(\kappa=0.73$; $95 \%$ CI $0.68-0.79$; quadraticweighted $\kappa=0.85)$ compared to the five scenarios where the 2008 guidelines would have suggested a different triage level $(\kappa=0.50 ; 95 \%$ CI $0.42-0.59$; quadratic-weighted $\kappa=0.54)$. Community triage nurses had a trend to a higher level of agreement $(\kappa=0.80 ; 95 \%$ CI 0.70-0.89; quadratic-weighted $\kappa=$ 0.88 ) for the five case scenarios that relied on the 2004 guidelines compared to their colleagues at the teaching hospital $(\kappa=0.71 ; 95 \%$ CI $0.63-0.78$; quadraticweighted $\kappa=0.83)$. Similarly, for the five case scenarios where the 2008 CTAS guidelines would have suggested a different triage level, community nurses had a trend to a higher level of agreement $(\kappa=$ 0.62 ; $95 \%$ CI 0.48-0.76; quadratic-weighted $\kappa=0.63$ ) compared to their colleagues at the teaching hospital $(\kappa=0.45$; 95\% CI 0.35-0.56; quadratic-weighted $\kappa=$ $0.50)$.

For the 10 case scenarios analyzed, the free-text presenting complaints matched the CEDIS list $90.1 \%$ of the time ( $\kappa=0.80 ; 95 \%$ CI $0.76-0.84)$. Triage nurses from the teaching hospital had a higher level of agreement, with $92.3 \%$ of the free-text presenting complaints matching the CEDIS list $(\kappa=0.85 ; 95 \%$ CI 0.80-0.89), compared to their colleagues at the community hospital, whose free-text entries matched the CEDIS list $85.6 \%$ of the time $(\kappa=0.71 ; 95 \%$ CI $0.63-0.80)$.

\section{DISCUSSION}

The CTAS has been shown to be a reliable tool with moderate to strong predictive validity in forecasting resource use..$^{4,12-18}$ In a single-center study observing the transition from the CTAS to the Emergency Severity Index (ESI), the CTAS was shown to have a higher sensitivity for identifying abdominal pain requiring intensive care unit or operative management or ED death, with similar performance for patients presenting with chest pain. ${ }^{2}$

Although the reliability of the CTAS guidelines has been well established through multiple studies, there is a paucity of research validating the reliability of the 2008 CTAS guideline revisions. This study assessed the reliability of the updated 2008 CTAS guidelines. There was good to very good agreement between all triage nurses using the 2004 CTAS guidelines compared to the 2008 guidelines, which achieved only moderate to good agreement. Community nurses trended toward a higher agreement with the 2004 CTAS guidelines than their academic colleagues and a significantly higher agreement for community nurses than for academic nurses for the 2008 guidelines. Furthermore, there was 
good intrarater agreement for all triage nurses, indicating that the 2004 CTAS guidelines and 2008 CTAS revisions were applied consistently over time. Previous studies reporting intrarater agreement found good agreement between triage nurses, but the number of participants in the intrarater arm of the study was quite low $(n=12){ }^{19}$

From this study, it appears that the CTAS tends to have a higher level of agreement at a community versus an academic ED; consequently, the distribution of community and academic triage nurses may have influenced reliability. Some have suggested various methods to rectify this issue, including computerassisted triage and regularly scheduled quality assurance measures..$^{20}$ Computer-assisted triage tools that are compliant with the CTAS have been developed to aid in the triage process. Presenting complaints are chosen from a standardized list, and a complaintspecific template assists in the assignment of the appropriate CTAS level. Agreement between nurses using a CTAS-based computer-assisted triage has been shown to be moderate to good. ${ }^{20}$

This study was not designed to distinguish if the 2008 CTAS revisions are more difficult to apply reliably or to detect a deficit in CTAS instruction and training. In reference to an ED triage clinical decision support system, it has been shown that interrater agreement among nurses trends toward improvement with additional training. ${ }^{20}$ Our study showed a trend toward community nurses having a higher agreement with the 2004 CTAS guidelines than their academic counterparts. The community nurses also had significantly higher agreement with the 2008 CTAS guidelines compared to their academic colleagues.

This study is not without limitations. Reliability was assessed using a small number of paper-based scenarios as opposed to observation of real-time triage in the ED. However, previous studies have shown good agreement between interrater reliability of paper-based case scenarios and live triage cases. ${ }^{21}$ With the large number of potential combinations of CTAS score and presenting complaints, these paper-based scenarios may not characterize a representative sample of ED triage cases to evaluate the reliability of CTAS scoring. Additionally, only one "gold standard" adjudicator assessed the agreement between free-text presenting complaints and the CEDIS complaint. The voluntary nature of the study introduces bias due to incomplete participation of all eligible nurses. Self-selection bias, or volunteer bias, is error due to systematic differences between the characteristics of participants and nonparticipants. The external validity or generalizability of this study may be compromised if there are differences among triage nurses who did and did not participate. Lastly, this study was conducted only at two institutions in a single province, so our findings may not be generalizable across the country.

\section{CONCLUSIONS}

The reliability of CTAS scoring by academic and community ED nurses for 10 paper-based scenarios was relatively good; however, the application of the 2008 CTAS revisions appears less reliable than the 2004 CTAS guidelines. These results may be useful to develop educational materials to strengthen reliability and validity for triage scoring using the 2008 CTAS guideline revisions.

Competing interests: None declared.

\section{REFERENCES}

1. Beveridge R, Clarke B, Janes L, et al. Canadian Emergency Department Triage and Acuity Scale: implementation guidelines. CFEM 1999;1(3 Suppl):S1-24.

2. Asaro P, Lewis L. Effects of triage process conversion on the triage of high-risk presentations. Acad Emerg Med 2008;15: 916-22, doi:10.1111/j.1553-2712.2008.00236.x.

3. Elkum N, Barrett C, Al-Omran H. Canadian Emergency Department Triage and Acuity Scale: implementation in a tertiary care center in Saudi Arabia. BMC Emerg Med 2011; $11: 3$.

4. Jimenez J, Murray M, Beveridge R, et al. Implementation of the Canadian Emergency Department Triage and Acuity Scale (CTAS) in the Principality of Andorra: can triage parameters serve as emergency department quality indicators? CFEM 2003;5:315-22.

5. Beveridge R. The Canadian Triage and Acuity Scale: a new and critical element in health care reform. 7 Emerg Med 1998;16:507-11, doi:10.1016/S0736-4679(98)00031-6.

6. Murray M, Bullard M, Grafstein E. Revisions to the Canadian Emergency Department Triage and Acuity Scale implementation guidelines. CFEM 2004;6:421-7.

7. Bullard M, Unger B, Spence J, et al. Revisions to the Canadian Emergency Department Triage and Acuity Scale (CTAS) adult guidelines. CFEM 2008;10:136-42.

8. Grafstein E, Unger B, Bullard $M$, et al. Canadian Emergency Department Information System (CEDIS) presenting complaint list (version 1.0). CFEM 2003;5:27-34.

9. Innes G, Murray M, Grafstein E, et al. A consensus-based process to define standard national data elements for a 
Canadian emergency department information system. CFEM 2001;3:277-84.

10. Grafstein E, Bullard M, Warren D, et al. Revision of the Canadian Emergency Department Information System (CEDIS) presenting complaint list version 1.1. CFEM 2008;10:151-61.

11. Landis J, Koch G. The measurement of observer agreement for categorical data. Biometrics 1977;33:159-74, doi:10.2307/ 2529310 .

12. Beveridge R, Ducharme J, Janes L, et al. Reliability of the Canadian Emergency Department Triage and Acuity Scale: interrater agreement. Ann Emerg Med 1999;34:155-9, doi:10.1016/S0196-0644(99)70223-4.

13. Manos D, Petrie DA, Beveridge RC, et al. Inter-observer agreement using the Canadian Emergency Department Triage and Acuity Scale. CFEM 2002;4:16-22.

14. Worster A, Gilboy N, Fernandes C, et al. Assessment of inter-observer reliability of two five-level triage and acuity scales: a randomized controlled trial. CFEM 2004;6:240-5.

15. Stenstrom R, Grafstein E, Innes G, et al. Real-time predictive validitiy of the Canadian Triage and Acuity Scale (CTAS) [abstract]. Acad Emerg Med 2003;10:512, doi:10.1197/aemj.10.5.512.

16. Murray MJ, Levis G. Does triage level (Canadian Triage and Acuity Scale) correlate with resource utilization for emergency department visits? [abstract]. CFEM 2004;6:180.

17. Worster A, Fernandes CM, Eva K, et al. Predictive validity comparison of two five-level triage acuity scales. Eur 7 Emerg Med 2007;14:188-92, doi:10.1097/MEJ.0b013e3280adc956.

18. Fernandes C, Tanabe P, Gilboy N, et al. Five-level triage: a report from the ACEP/ENA Five-Level Triage Task Force. 7 Emerg Nurs 2005;31:39-50, doi:10.1016/j.jen.2004.11.002.

19. Fernandes C, Wuerz R, Clark S, et al. How reliable is emergency department triage? Ann Emerg Med 1999;34:1417, doi:10.1016/S0196-0644(99)70248-9.

20. Dong S, Bullard M, Meurer D, et al. The effect of training on nurse agreement using an electronic triage system. C7EM 2007;9:260-6.

21. Worster A, Sardo A, Eva K, et al. Triage tool inter-rater reliability: a comparison of live versus paper case scenarios. 7 Emerg Nurs 2007;33:319-23, doi:10.1016/j.jen.2006.12.016.

\section{APPENDIX: CASE SCENARIOS}

This study involves triaging paper-based scenarios according to the CTAS guidelines. Please place the appropriate triage score (1-5) and presenting complaint for the following case scenarios.

Scenario 1: A 45-year-old male arrives with vital signs absent. He was snowblowing when he collapsed. Cardiopulmonary resuscitation (CPR) is in progress, he has been intubated, and he is receiving advanced care for ventricular fibrillation.

CTAS score:

\section{CTAS 1 Resuscitation}

CTAS 2 Emergent

CTAS 3 Urgent

CTAS 4 Less urgent

CTAS 5 Nonurgent

Presenting complaint:

Scenario 2: A 20-year-old female arrives with left ankle pain for 1 day. She everted her ankle when she was walking. Pain is $4 / 10$. She is weight bearing on the ankle.

CTAS score:

\section{CTAS 1 Resuscitation \\ CTAS 2 Emergent \\ CTAS 3 Urgent \\ CTAS 4 Less urgent \\ CTAS 5 Nonurgent}

Presenting complaint:

Scenario 3: A 50-year-old female arrives with cough and fever for 1 week. She is on atorvastatin (Lipitor), has no allergies, and has a past history of pneumonia. She is a smoker; there is no chest pain.

CTAS score:
CTAS 1 Resuscitation
CTAS 2 Emergent
CTAS 3 Urgent
CTAS 4 Less urgent
CTAS 5 Nonurgent

Presenting complaint:

Scenario 4: A 20-year-old male arrives with dental pain for 2 days. He is on ibuprofen and has no allergies. There has been no fever, swelling, or drainage. Pain is $4 / 10$. Vital signs are temperature $37^{\circ} \mathrm{C}\left(98.6^{\circ} \mathrm{F}\right)$, heart rate 80 beats/minute, blood pressure $110 / 70 \mathrm{~mm} \mathrm{Hg}$, and respiratory rate 16 breaths/minute.

CTAS score:

\section{CTAS 1 Resuscitation \\ CTAS 2 Emergent \\ CTAS 3 Urgent \\ CTAS 4 Less urgent \\ CTAS 5 Nonurgent}

Presenting complaint:

Scenario 5: A 30-year-old male arrives with left flank pain for 1 hour. He has had renal colic three times previously. He has vomited twice. There is no fever, no dysuria, and no frequency. He is on no medications and has no allergies. Pain is 6/10. Vital signs are temperature $37^{\circ} \mathrm{C}\left(98.6^{\circ} \mathrm{F}\right)$, heart rate 90 beats/minute, 
blood pressure 120/90 $\mathrm{mm} \mathrm{Hg}$, and respiratory rate 16 breaths/minute.

CTAS score:

CTAS 1 Resuscitation

CTAS 2 Emergent

CTAS 3 Urgent

CTAS 4 Less urgent

CTAS 5 Nonurgent

Presenting complaint:

Scenario 6: A 20-year-old female is suicidal for 1 day. She has a past history of psychiatric hospitalization for depression. There is no other relevant medical history. She is on paroxetine (Paxil) and has no allergies. She has a plan for hanging herself. She is a smoker and takes no street drugs or alcohol. Vital signs are temperature $37^{\circ} \mathrm{C}\left(98.6^{\circ} \mathrm{F}\right)$, heart rate 90 beats/minute, blood pressure 110/90 $\mathrm{mm} \mathrm{Hg}$, and respiratory rate 18 breaths/minute. She has poor eye contact. She is oriented, with no signs of intoxication.

CTAS score:

CTAS 1 Resuscitation

CTAS 2 Emergent

CTAS 3 Urgent

CTAS 4 Less urgent

CTAS 5 Nonurgent

Presenting complaint:

Scenario 7: A 55-year-old male arrives with left chest pain for 1 hour, radiating to the left arm. He has had a previous myocardial infarction and a history of dyslipidemia and hypertension. He is on nitroglycerin, aspirin, atorvastatin, and ramipril. He has no allergies. His pain is $7 / 10$. He has vomited twice and got some relief from nitroglycerin given twice in the ambulance. Vital signs are temperature $36.5^{\circ} \mathrm{C}\left(97.7^{\circ} \mathrm{F}\right)$, heart rate 60 beats/minute, blood pressure 140/90 $\mathrm{mm} \mathrm{Hg}$, and respiratory rate 20 breaths/minute. Bibasilar crackles are heard in his lung fields.

CTAS score:

CTAS 1 Resuscitation

CTAS 2 Emergent

$\square$ CTAS 3 Urgent

CTAS 4 Less urgent

CTAS 5 Nonurgent

Presenting complaint:
Scenario 8: A 25-year-old female arrives with mild vaginal bleeding for 2 hours. She has also had lower abdominal cramps. She is 6 weeks pregnant. She takes no medications and has no allergies. She has $4 / 10$ pain. Vital signs are temperature $37^{\circ} \mathrm{C}\left(98.6^{\circ} \mathrm{F}\right)$, heart rate 100 beats/minute, blood pressure $120 / 80 \mathrm{~mm} \mathrm{Hg}$, and respiratory rate 16 breaths/minute.

CTAS score:

\section{CTAS 1 Resuscitation \\ CTAS 2 Emergent \\ CTAS 3 Urgent \\ CTAS 4 Less urgent \\ CTAS 5 Nonurgent}

Presenting complaint:

Scenario 9: A 30-year-old male arrives with left hip pain for 1 hour. He fell off his snowmobile and hit a tree. $\mathrm{He}$ is on no medication and has no allergies. $\mathrm{He}$ has no previous medical or surgical history. His pain is 6/10. Vital signs are temperature $37.2^{\circ} \mathrm{C}\left(98.9^{\circ} \mathrm{F}\right)$, heart rate 100 beats/minute, blood pressure $130 / 90 \mathrm{~mm}$ $\mathrm{Hg}$, and respiratory rate 20 breaths/minute. His left hip is internally rotated and flexed. He has good pulses and sensation, with limited range of motion.

CTAS score:

\section{CTAS 1 Resuscitation \\ CTAS 2 Emergent \\ CTAS 3 Urgent \\ CTAS 4 Less urgent \\ CTAS 5 Nonurgent}

Presenting complaint:

Scenario 10: A 16-year-old male arrives with fever for 4 hours. He has a history of leukemia and is on chemotherapy. He has no cough, no chest pain, no abdominal pain, no vomiting, no diarrhea, no dysuria, and no frequency. He has no allergies. Vital signs are temperature $39.5^{\circ} \mathrm{C}\left(103.1^{\circ} \mathrm{F}\right)$, heart rate 120 beats/ minute, respiratory rate 20 breaths/minute, and blood pressure 110/70 $\mathrm{mm} \mathrm{Hg}$.

CTAS score:

CTAS 1 Resuscitation

CTAS 2 Emergent

CTAS 3 Urgent

CTAS 4 Less urgent

CTAS 5 Nonurgent

Presenting complaint: 